\title{
ADHERENCE TO TWO METHODS OF EDUCATION AND METABOLIC CONTROL IN TYPE 2 DIABETICS
}

\author{
Verónica R. Gutiérrez Herrera ${ }^{1}$, Hugo Mendieta Zerón ${ }^{2}$, Martha R. Mendieta \\ Alcántara $^{3}$
}

\begin{abstract}
BACKGROUND: Education in diabetes optimizes metabolic control, prevents acute and chronic complications, and improves quality of life. Our main objective was to evaluate if a better metabolic control is achieved in diabetic patients undergoing a program of intensive interactive care than in those with traditional care and written information.

METHODS: Patients with type 2 diabetes mellitus (T2DM), aged 20-60 years, education level at least of primary school, serum creatinine $\leq 2.5 \mathrm{mg} / \mathrm{dl}$, self-sufficient and $\mathrm{Hb} A 1 \mathrm{c} \geq 7.1 \%$ were allocated in two groups of education, 1) minimal education (MEG) and 2) full education (FEG). The MEG patients followed predefined diet; FEG patients chose the diet by selecting foods from each group in a list of matches, teaching them to count nutrients, kilocalories (kcal) and percentage of nutrients.

RESULTS: A follow-up of 31 patients in each group was obtained. The proportion of patients who had initial adherence was $13.33 \%$ in the MEG group and $9.67 \%$ in the FEG group while, at the end of the study, these percentages were of $73.3 \%$ and $58.38 \%$ respectively. The final HbAlc decreased in both groups, with or without good adherence. The FEG group had a higher decline in the values of cholesterol $(p=0.036)$ and LDL $(p=0.002)$ than the MEG group.

CONCLUSION: Education programs in T2DM contribute to a decrease in HbAlc within six months, but an intensive program is more effective in reducing cholesterol and $L D L$.

KEYWORDS: diabetes mellitus, education, metabolic control.
\end{abstract}

DOI: http://dx.doi.org/10.4314/ejhs.v25i2.9

\section{INTRODUCTION}

Latin America is one of the regions with a highest increase in the incidence of type 2 diabetes mellitus (T2DM) (1), which is the leading cause of death in Mexico (2). Since 1875, Boucharat promoted the education of diabetic patients with the daily urine test and weight loss monitoring as cornerstones in the follow-up of patients with diabetes (3).

As noted by the World Health Organization (WHO), many patients do not understand the medical indications, less than $50 \%$ continue their treatment correctly, patients are informed inappropriately about their condition and few are geared to manage and take responsibility of their own treatment (4). As a result, education about self-care strategy is mandatory to all patients.

Training for diabetes self-management is the process of teaching individuals to manage their own conditions, and is considered an important part of clinical management (5). The goals of diabetes education are to optimize metabolic control, prevent acute and chronic complications, and improve the quality of life (6). As a matter of fact, there is knowledge deficiency and skills in diabetes patients up to $50-80 \%$ (7), and glycemic control with glycated hemoglobin (HbAlc) < $7.0 \%$ is achieved in less than half of people with diabetes (8).

\footnotetext{
${ }^{1}$ Faculty of Medicine, Autonomous University of the State of Mexico (UAEMex)

${ }^{2}$ Asociación Científica Latina A.C. (ASCILA) and Ciprés Grupo Médico (CGM)

${ }^{3}$ Diabetes Clinic, Regional Hospital "Gral. Ignacio Zaragoza", ISSSTE

Corresponding Author: Martha Ruth Mendieta Alcántara, Email:urania2100@yahoo.com.mx
} 
Educational techniques have evolved and changed into educational interventions that involve the patient in decision-making programs (9). Our main objective was to evaluate whether a better metabolic control is achieved in diabetic patients undergoing a program of intensive interactive care (full education) than in those with traditional care and written information (low education)at the Clínica de Diabetes, Hospital Regional "Gral. Ignacio Zaragoza", ISSSTE, Mexico City, Mexico.

\section{MATERIALS AND METHODS}

Patients: We invited patients with T2DM, aged 20-60 years, education level of at least primary school, serum creatinine $\leq 2.5 \mathrm{mg} / \mathrm{dl}$, selfsufficient and $\mathrm{HbAlc} \geq 7.1 \%$. Those patients not willing to participate were excluded and those missing an appointment during the study were discarded.

Sample: Accepting an alpha risk of 0.05 and a beta risk of 0.2 in a two-sided test, 28 subjects per group were necessary to recognize as statistically significant a difference greater than or equal to 1.2 units in glycated hemoglobin. The common standard deviation was assumed to be 1.6. A dropout rate of $0 \%$ was anticipated.

Education strategies: patients were allocated sequentially into two groups of education: 1) minimal education (MEG) and 2) full education (FEG). To reduce selection bias, the medical staff did not do the patient appointment. The MEG patients followed a predefined diet; each of them was given the amount of food rations. FEG patients chose the diet by selecting foods from each group in a list of matches, teaching them to count nutrients, kilocalories (kcal) and percentage of nutrients; in both groups, the aim was to achieve the objectives of the American Diabetes Association (ADA). MEG patients were attended on Mondays and FEG patients on Wednesdays. All patients during the first month were cited each week and then every month until 6 months.

After blood samples, from 9 to 10 am patients had breakfast and filled the directed history (only on the first date), a survey of ingested kcal in the previous 24 hours and a questionnaire about diabetes. Two hours post-breakfast glucose was measured, and the FEG group received education on diet, self-monitoring, exercise, ADA therapeutic objectives and chronic complications through classes and workshops, while the MEG group received written information and explanations only under the patients' request.

The program included explanations about overweight, diet selection, exercise, screening and improved metabolic control, smoking cessation, taking medications and prevention of complications.

A learning assessment was made with the following topics: a) preparation of menus for 3 meals per day, b) identification of food portions based on $\mathrm{kcal} / \mathrm{day}$ and $\mathrm{kcal} / \mathrm{carbohydrate}$, protein and fat (only the education group), c) identification of self-monitoring with emphasis on hypoglycemia and hyperglycemia, d) practice exercise, and e) comparison of drugs and dosage from those indicated.

Anthropometric measures: Height (m) and weight (kg) (Seca, GmbH, Germany) were measured in a standing position. BMI was calculated as weight $(\mathrm{kg})$ divided by height $(\mathrm{m})$ squared. Blood pressure was measured with a mercury sphygmomanometer after 5 min of rest.

Diet: A 24-hour dietary recall was used for this purpose. Diet was categorized within three choices: 1) consumption of $80 \%-120 \%$ of the indicated kcal, 2) less than $80 \%$ of the indicated $\mathrm{kcal}$, and 3) greater than $120 \%$ of kcal indicated. Diet was classified as dichotomous whether or not it had a balanced proportion of 50\%-60\% carbohydrates, $10 \%-20 \%$ protein and $<30 \%$ fat. The calculated kcal was based on the ideal weight minus $200 \mathrm{kcal} /$ day in cases of overweight.

Exercise: Exercise (intensive walking; running or cycling) was reported in days per week of physical activity and $\mathrm{min} /$ day. A specific activity was not prescribed due to the heterogeneous work schedule and physical conditions of the patients.

Laboratory: Patients arrived at 7:30 am, after fasting for 12 hours. Venous samples were taken in Vacutainer ${ }^{\mathrm{TM}}$ tubes for the determination of glucose, total cholesterol (TC), high-density cholesterol (HDL-C), low-density cholesterol (LDL-C), triglycerides and uric acid (Hitachi 917 (B) autoanalizer) and HbA1c. Capillary blood glucose was measured with a Precision ${ }^{\circledR}$ glucose monitor. Serum glucose was measured using the glucose oxidase method and the HbAlc with the turbidimetric inhibition immunoassay (TINIA) method (Roche).

Statistics: Intragroup and intergroup differences between baseline and 6 months' values were 
analyzed with the Student's t test. Odds Ratio (OR) was used to evaluate the percentage of diet adherence and metabolic control. Pearson correlation was used to determine the relation between metabolic control and exercise and logistic regression analysis for "adherence" was also developed. A p value less than 0.05 was considered significant. All tests were performed with the SPSS v. 15 program.

Ethics: The ethical and research committee of Ciprés Grupo Médico (CGM), Code 2014/01 approved this study. The procedures followed were in accordance with the ethical standards of the General Health Law of Mexico and were Table 1: General characteristics of the population (mean \pm 1 standard deviation)

\begin{tabular}{|c|c|c|c|c|}
\hline & & & & \\
\hline & Minin & & $\mathbf{F u}$ & \\
\hline & Mean \pm SD & Range & Mean \pm SD & Range \\
\hline Age (years) & $51 \pm 8$ & $29-64$ & $49 \pm 8$ & $33-66$ \\
\hline Women & $51.4 \pm 8.2$ & $35-64$ & $48 \pm 8.4$ & $33-66$ \\
\hline Men & $49.7 \pm 8.4$ & $29-60$ & $48.7-8.2$ & $36-60$ \\
\hline Evolution (years) & $6.90 \pm 4.87$ & $.08-17$ & $7.35 \pm 6.8$ & $0.33-25.00$ \\
\hline $\mathrm{BMI}^{\mathrm{a}}$ & $28.85 \pm 5.23$ & $17.8-42.2$ & $28.4 \pm 3.7$ & $20.5-36.1$ \\
\hline $\mathrm{BMI} \dagger$ & $28.66 \pm 4.84$ & $19.1-41.7$ & $28.9 \pm 3.8$ & $20.0-35.8$ \\
\hline $\mathrm{SBP}(\mathrm{mmHg})^{\mathrm{a}}$ & $122 \pm 19$ & $100-180$ & $126 \pm 18$ & $100-160$ \\
\hline $\mathrm{SBP}(\mathrm{mmHg}) \dagger$ & $120 \pm 19$ & $90-170$ & $122 \pm 14$ & $100-150$ \\
\hline $\mathrm{DBP}(\mathrm{mmHg})^{\mathrm{a}}$ & $76 \pm 13$ & $60-100$ & $79 \pm 15$ & $60-130$ \\
\hline $\mathrm{DBP}(\mathrm{mmHg}) \dagger$ & $77 \pm 14$ & $50-120$ & $74 \pm 8$ & $60-90$ \\
\hline C-glu (mg/dl) & $218 \pm 73$ & $126-400$ & $217 \pm 84$ & $76-426$ \\
\hline C-glu $(\mathrm{mg} / \mathrm{dl}) \dagger$ & $140 \pm 63$ & $6-274$ & $151 \pm 55$ & $65-271$ \\
\hline $2 \mathrm{hBG}(\mathrm{mg} / \mathrm{dl})^{\mathrm{a}}$ & $265 \pm 96$ & $115-450$ & $232 \pm 87$ & $61-429$ \\
\hline $2 \mathrm{hBG}(\mathrm{mg} / \mathrm{dl}) \dagger$ & $156 \pm 71$ & $61-319$ & $189 \pm 56$ & $103-324$ \\
\hline V-glu $(\mathrm{mg} / \mathrm{dl})^{\mathrm{a}}$ & $226 \pm 91$ & $61-530$ & $241 \pm 87$ & $98-400$ \\
\hline V-glu $(\mathrm{mg} / \mathrm{dl}) \dagger$ & $146 \pm 68$ & $77-373$ & $174 \pm 94$ & $87-546$ \\
\hline $\mathrm{HbA} 1 \mathrm{C}^{\mathrm{a}}$ & $11.27 \pm 2.46$ & $7.5-18.3$ & $10.8 \pm 2.4$ & $7.2-16.7$ \\
\hline $\mathrm{HbA} 1 \mathrm{C} \dagger$ & $7.73 \pm 1.59$ & $6.0-12.4$ & $7.7 \pm 1.6$ & $5.6-12.1$ \\
\hline $\mathrm{TC}(\mathrm{mg} / \mathrm{dl})^{\mathrm{a}}$ & $219 \pm 40$ & $145-334$ & $210 \pm 52$ & $142-405$ \\
\hline $\mathrm{TC}(\mathrm{mg} / \mathrm{dl}) \dagger^{*}$ & $213 \pm 40$ & $151-308$ & $186 \pm 45$ & $126-303$ \\
\hline $\mathrm{TG}(\mathrm{mg} / \mathrm{dl})^{\mathrm{a}}$ & $265 \pm 173$ & $48-908$ & $270 \pm 228$ & $87-1160$ \\
\hline $\mathrm{TG}(\mathrm{mg} / \mathrm{dl}) \dagger$ & $204 \pm 114$ & $63-510$ & $219 \pm 112$ & $58-412$ \\
\hline $\operatorname{HDL}(\mathrm{mg} / \mathrm{dl})^{\mathbf{a}}$ & $46 \pm 13$ & $27-95$ & $43 \pm 10$ & $31-69$ \\
\hline $\mathrm{HDL}(\mathrm{mg} / \mathrm{dl}) \dagger$ & $49 \pm 14$ & $34-101$ & $47 \pm 11$ & $28-73$ \\
\hline $\mathrm{LDL}(\mathrm{mg} / \mathrm{dl})^{\mathbf{a}}$ & $123 \pm 44$ & $13-247$ & $112 \pm 35$ & $46-182$ \\
\hline $\operatorname{LDL}(\mathrm{mg} / \mathrm{dl}) \dagger^{* *}$ & $125 \pm 29$ & $77-187$ & $94 \pm 37$ & $27-170$ \\
\hline
\end{tabular}

\section{Diet}

One hundred percent of the patients wrote back the diet report. There was a decrease in the kcal subjected to the ethical and moral value judgments of Helsinki.

\section{RESULTS}

Patients: A follow-up of 31 patients with minimum education (14 women and 17 men) and 31 patients with full education (11 women and 20 men) was completed. The average age of patients was $51 \pm 8$ years for the MEG patients and $49 \pm 8$ for the FEG patients. Both groups showed similar education level (10.4 \pm 3.3 years of education in the MEG group and $12.5 \pm 3$ years in the FEG group) as shown in Table 1. 
Table 2: Diet adherence*

\begin{tabular}{|lcccc|}
\hline $\begin{array}{l}\text { Kcal intake } \\
\text { indicated }\end{array}$ & \multicolumn{2}{c}{ Minimum ed of } & Group & \multicolumn{2}{c|}{ Full education } \\
& Basal & After 6 months & Basal & After 6 months \\
\hline $80-120$ & 13 & 28 & 21 & 29 \\
$>120$ & 6 & 2 & 4 & 0 \\
< 80 & 11 & 0 & 6 & 2 \\
\hline *: Patients who reported diet in minimum education: 30 , in full education: 31 & \\
\hline
\end{tabular}

The proportion of patients who had initial diet adherence was $13.33 \%$ in the MEG group and $9.67 \%$ in the FEG group while at the end of the study these percentages were $73.3 \%$ and $58.38 \%$ respectively. Interestingly, the final $\mathrm{HbA} 1 \mathrm{c}$ decreased in both groups, with or without good adherence.

At the beginning of the study, there were 11 patients with a balanced diet and 19 with an unbalanced diet in the MEG group. After six months, the frequency changed to 24 and 6 respectively. In the FEG group, there were 5 patients with a balanced and 26 with an unbalanced diet at the beginning of the study- these numbers changed to 18 and 13 after six months.

For three different situations in diet condition and metabolic control (HbA1c > 7), the highest OR (1.06) was for unbalanced diet and 80\%-120\% adherence vs other combinations (balance and adherence) in diet (Table 3). Likewise, in the MEG group, the initial value of HbA1c was $10.7 \%$ in case of diet adherence and $12.8 \%$ without adherence, and after six months, the percentages changed to $7.59 \%$ and $7.55 \%$ respectively. In the FEG group, the values changed from $11.84 \%$ to $7.4 \%$ and $10.51 \%$ to $7.28 \%$ for the same conditions.

Table 3: ORs for $\mathrm{HgAlc}>7$

\begin{tabular}{|c|c|c|c|}
\hline Comparison & 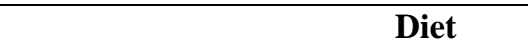 & OR & $95 \% \mathrm{CI}$ \\
\hline 1 & $\begin{array}{l}\text { Unbalanced and 80-120\% adherence } \\
\text { Others }\end{array}$ & 1.06 & 0.36 to 3.16 \\
\hline 2 & $\begin{array}{l}\text { Unbalanced and }<80 \% \text { adherence } \\
\text { Others }\end{array}$ & 0.57 & 0.03 to 9.72 \\
\hline 3 & $\begin{array}{l}\text { Balanced and } 80-120 \% \text { adherence } \\
\text { Unbalanced and } 80-120 \% \text { adherence }\end{array}$ & 0.56 & 0.18 to 1.75 \\
\hline
\end{tabular}

We also noted that Pearson test in females $(n=32)$ showed a positive significant correlation between adherence and carbohydrate intake $(\mathrm{p}=0.002)$. On the contrary, the correlation was negative to proteins when the analysis was made only in males $(n=17)(p=0.026)$; in this subgroup, the diet portion of lipid was also significant. We also found that Pearson test showed a positive correlation for adherence and "kcalei".

By logistic regression analysis with the dependent variable "adherence", the only independent variable with statistically significant difference was "kcalei" (percentage of indicated caloric intake).

Exercise: In the specific topic of exercise, the MEG group began the study with nine patients practising it, and after the observation period, 23 patients were motivated to practise physical movement. In the FEG group, these numbers were
10 and 31 respectively. We ended the study with an average exercise of 2.89 days per week in the MEG group and 4.54 in the FEG group.

Self-control and knowledge evaluation: At the beginning of the study, none of the patients reported self-control capabilities and after the intervention program; the percentages reached were of 89.51 in the MEG group and 68.92 in the FEG group.

The general diabetes knowledge examination test gave a result of 1.79 in the MEG group at the beginning and 8.16 in the end, while the FEG group had values of 1.77 and 8.51 (all in scale from 0 to 10 points).

Laboratory: The change in value ranges in metabolic variables are presented in Table 4 . The FEG group had a higher decline in the values of cholesterol $(p=0.036)$ and LDL $(p=0.002)$ than the MEG group. 
Table 4: Variables by rank

\begin{tabular}{|c|c|c|c|c|}
\hline & Minimu & on (patients) & Full & (patients) \\
\hline & Initial & After 6 months & Initial & After 6 months \\
\hline $\mathrm{SBP}(\mathrm{mm}$ & & & & \\
\hline$\leq 120$ & 20 & 20 & 17 & 23 \\
\hline $121-140$ & 6 & 10 & 8 & 4 \\
\hline$>140$ & 5 & 1 & 6 & 4 \\
\hline $\mathrm{DBP}(\mathrm{mm}$ & & & & \\
\hline$\leq 80$ & 25 & 28 & 25 & 28 \\
\hline $81-90$ & 2 & 3 & 1 & 2 \\
\hline$>90$ & 4 & 0 & 5 & 1 \\
\hline HbA1c $(?$ & & & & \\
\hline$\leq 7$ & 0 & 9 & 0 & 13 \\
\hline $7.1-8$ & 2 & 9 & 5 & 10 \\
\hline$>8$ & 29 & 13 & 26 & 8 \\
\hline $\mathrm{TC}(\mathrm{mg} / \mathrm{d}$ & & & & \\
\hline$\leq 200$ & 10 & 14 & 16 & 20 \\
\hline $201-250$ & 13 & 15 & 11 & 9 \\
\hline$>250$ & 8 & 2 & 4 & 2 \\
\hline $\mathrm{TG}(\mathrm{mg} / \mathrm{c}$ & & & & \\
\hline$\leq 150$ & 8 & 10 & 13 & 16 \\
\hline $151-200$ & 4 & 7 & 2 & 3 \\
\hline$>200$ & 19 & 14 & 16 & 12 \\
\hline HDL-C ( & & & & \\
\hline$\leq 45$ & 17 & 17 & 20 & 18 \\
\hline $45.1-60$ & 12 & 9 & 8 & 11 \\
\hline$>60$ & 2 & 5 & 3 & 2 \\
\hline
\end{tabular}

In relation to renal function, in the MEG group, two patients began with creatinine higher than $1.25 \mathrm{mg} / \mathrm{dl}$, and three finished with values higher than this with one requiring dialysis. In this group, seven patients began with uric acid higher than 7 $\mathrm{mg} / \mathrm{dl}$ while ten patients ended the study with this value or higher. In the FEG group, one patient began with creatinine higher than $1.25 \mathrm{mg} / \mathrm{dl}$, and three patients finished the study with values above this. Paradoxically, at the beginning of the intervention, none of the patients had uric acid above $7 \mathrm{mg} / \mathrm{dl}$, but there were five at the end.

Metabolically ( $\mathrm{HbA} 1 \mathrm{C})$, the change shows that in the MEG group, the percentage of controlled patients was $0 \%$ in the beginning and $20 \%$ reached clinical targets after six months. In the FEG group, the variation increased from $0 \%$ to $18.18 \%$.

In relation to the total cholesterol, in the MEG group, the percentage of controlled patients at baseline was only $32.2 \%(\mathrm{~N}=31)$ and $32 \%(\mathrm{~N}$ $=25$ ) at the end, while in the FEG group, the percentage increased from $51.6 \%(\mathrm{~N}=31)$ to
$59.0 \%(\mathrm{~N}=22)$. The triglycerides showed a good trend control from $25.8 \%(\mathrm{~N}=31)$ to $40 \%(\mathrm{~N}=$ $25)$ in the first group and diminished from $45.1 \%$ $(\mathrm{N}=31)$ to $27.2 \%(\mathrm{~N}=22)$ in the second one. The HDL-C greater than 60 was kept in two cases in the first group, and in three cases, in the second group.

According to the Student $t$ test, there were statistically significant differences $(p \leq 0.001)$ between initial and last values of the next variables: $\mathrm{HgA} 1 \mathrm{c}$, fasting serum glucose, fasting capillary, 2 hours post breakfast capillary, total cholesterol, triglycerides, HDL, and LDL this among all patients without grouping. Intergroup $\mathrm{T}$ test (MEG vs FEG) showed a difference for total cholesterol $(p=0.036)$ and LDL $(p=0.002)$ at the sixth month.

The Wilcoxon test for the MEG group evidenced significant differences between the initial recruiting and after six months' follow-up values for BMI $(\mathrm{p}=0.042)$, serum fasting glucose $(\mathrm{p}=0.002), 2$ hours post breakfast capillary $(\mathrm{p}=$ $0.002)$, fasting capillary $(\mathrm{p}=0.006), \mathrm{HbA} 1 \mathrm{C}$ and 
HDL $(p=0.021)$. The same test in the FEG group demonstrated significant differences in serum fasting glucose $(\mathrm{p}=0.001)$, fasting capillary $(\mathrm{p}=$ $0.007)$, HbA1C, total cholesterol $(\mathrm{p}=0.020), \mathrm{HDL}$ $(\mathrm{p}=0.036)$ and LDL $(\mathrm{p}=0.002)$.

An inverse relationship was observed between minutes of exercise and $\mathrm{HbA} 1 \mathrm{c}$, which was demonstrated by linear regression and Pearson correlation. It is interesting to note that our patients decreased their level of $\mathrm{HgAlc}$ at a greater rate in the MEG group than the FEG group.

Drugs: From the MEG group, four patients were taking pravastatin and two were taking fibrates at the beginning; one was able to avoid the drug. At the end, this group registered six patients with pravastatin and three with fibrates. In the FEG group, three patients were taking pravastatin, one of them later suspended this drug but at the end, another one had to be prescribed with this treatment.

It is notable that only two patients in the MEG group did not require a change in the therapeutic scheme, contrasting with the other 60 .

\section{DISCUSSION}

T2DM can be effectively controlled with an intervention model based on group care, which emphasizes the interactive educational techniques stimulating patient cooperation. Nevertheless, educational programs are very demanding for the healthcare staff, requiring a lot of time, specific training and communication skills. Points to consider for an ideal self-management intervention are feasibility, practicality in a wide variety of cases, motivation, and effectiveness to maintain important physiological results in the long term, improving the quality life (10).

Norris et al. (11) conducted a systematic review of self-care training in $\mathrm{T} 2 \mathrm{DM}$, concluding that the intervention effects on lipids, physical activity, weight and blood pressure were variable. In this respect, some studies that have measured changes in diabetes show improvement when adding an education program (12-14), but longlasting studies are disappointing. For example, Wing et al. (15) focused on adjustments in diet and physical activity in conjunction with selfmonitoring of serum glucose, identified a failure in showing glycemic improvement after one year. By comparison, we can see that virtually all patients evolved to a better condition, but six months is insufficient to achieve the ADA goals (HbA1c: 7\%; preprandial plasma glucose: 70-130 $\mathrm{mg} / \mathrm{dl}$; postprandial plasma glucose: less than 180 $\mathrm{mg} / \mathrm{dl})$. With the advancement of science and technology, a step forward would be enough to harness the Internet to allow patients to selfmonitor and keep updated through the website of the health institutions, as has already been experienced (16).

Most studies evaluating dietary changes have shown positive results in self-reports, including improvement in the intake of carbohydrates and lipids and a decrease in total kcal (17-18). Educational interventions in diabetes with a short follow-up up to 6 months tended to show greater efficacy (19-20). In this survey, education, either intensive or usual, seems to achieve normalization in Kcal ingestion.

In this study, in the MEG group, the number of patients practising exercise increased 2.5 times more, while in the FEG this increase was of 3.1. To some extent, this is consistent with Wood (21) who noted an increase in physical activity after 4 months of intervention, Glasgow et al. (22) that found an increase in the number of minutes of activity three months after intensive education and Wierenga (23) who found an increase in physical activity after 5 sessions at the 4 month.

Group-based training for self-management strategies in people with T2DM is effective in improving fasting blood glucose levels, HbA1C and diabetes knowledge and reducing systolic blood pressure levels, body weight and the requirement for diabetes medication (24). Maintaining an average $\mathrm{HbA1C}$ decrease might lead to a decrease in the lifetime to develop microalbuminuria, neuropathy and retinopathy (25). The decrease in blood pressure and lipid levels help reduce cardiovascular risk (26). As published by several authors (27-28), our results also show changes in some variables after implementing an educational program.

Drug therapy is indicated if the response to altered diet and exercise is inadequate (29). This study provides an important insight as to the possibility of achieving adequate metabolic control in diabetic patients managed with glyburide, metformin and insulin in health institutions with limited resources. 
A proactive management plan should include patient-centered goals for controlling hypertension, lipid levels, and glycaemia (30). Several aspects of our group care model deserve special attention. First, it was effective in promoting appropriate health behaviors and metabolic improvement leading to a decline in BMI. Second, this technique stabilized HbA1c and increased HDL. Moreover, the difference in HbA1c remained significant after adjustment for BMI. Similarly, the multivariate analysis showed that $\mathrm{HbA} 1 \mathrm{c}$ improvement did not depend on age and duration of diabetes.

Now, it is perfectly demonstrated that intensive control prevents complications of diabetes, but it is difficult to keep a group with the same strategy for a long time. From our data, we recommend that each diabetes clinic evaluate the time at which losses exceed $20 \%$ of a total cohort in follow up to design strategies to keep patients in close monitoring. This should set the parameters for a national strategy in order to keep patients on surveillance. In our population, we can say, in general, that fewer kcal in proteins or fats is related to a better adherence.

Despite intensive intervention, lifestyle changes and drug treatment, there is a progressive worse metabolic control in patients with T2DM (31). One reason for the poor results in individuals with diabetes is the lack of eligibility in the intervention program. Motivation is a key to acquire knowledge, and keep adherence in a hard life regimen. Our results reinforce the need for and the benefits of incorporating education in selected patients. Effective programs for self-care of diabetes should not be complex, need be individualized and reinforced over time (32).

While further work is required to define the effectiveness of interventions aimed at self-care in T2DM on sustained glycemic control in detail, two limitations of our study are the small number of patients and the non-randomization process to offer the education method. It is worth noting the positive benefits in a short time (six months) and with a minimum medical staff. These results might be bolstered with a better patient selection based on education level.

\section{ACKNOWLEDGEMENT}

The authors thank Roche Mexico whose reagent was donated for the HbA1c determination.

\section{REFERENCES}

1. Ginter E, Simko V. Type 2 diabetes mellitus, pandemic in 21st century. Adv Exp Med Biol, 2012;771:42-50.

2. Díaz de León-Castañeda C, AltagraciaMartínez M, Kravzov-Jinich J, CárdenasElizalde Mdel R, Moreno-Bonett C, MartínezNuñez JM. Cost-effectiveness study of oral hypoglycemic agents in the treatment of outpatients with type 2 diabetes attending a public primary care clinic in Mexico City. Clinicoecon Outcomes Res, 2012;4:57-65.

3. Bouchardat A. De la glycosurie ou diabéte sucré. Paris: Libraire Germer Bailliere; 1875.

4. Report of a WHO working group. Therapeutic patient education. Continuing education programmes for healthcare providers in the field of prevention of chronic diseases. World Healh Organzation. Regional Office for Europe. Copenhagen. 1998.

5. Brown SA, Hanis CL. Lessons Learned from 20 Years of Diabetes Self-Management Research With Mexican Americans in Starr County, Texas. Diabetes Educ, 2014.

6. Chao A, Whittemore R, Minges KE, Murphy KM, Grey M. Self-management in early adolescence and differences by age at diagnosis and duration of type 1 diabetes. Diabetes Educ, 2014;40(2):167-77.

7. Clement S. Diabetes self-management education. Diabetes care 1995;18(8):1204-14.

8. Harris MI, Eastman RC, Cowie CC, Flegal KM, Eberhardt MS. Racial and ethnic differences in glycemic control of adults with type 2 diabetes. Diabetes care, 1999;22(3):403-8.

9. Marrero DG, Ard J, Delamater AM, et al. Twenty-first century behavioral medicine: a context for empowering clinicians and patients with diabetes: a consensus report. Diabetes care, 2013;36(2):463-70.

10. Glasgow RE, La Chance PA, Toobert DJ, Brown J, Hampson SE, Riddle MC. Longterm effects and costs of brief behavioural dietary intervention for patients with diabetes 
delivered from the medical office. Patient Educ Couns, 1997;32(3):175-84.

11. Norris SL, Engelgau MM, Narayan KM. Effectiveness of self-management training in type 2 diabetes: a systematic review of randomized controlled trials. Diabetes care, 2001;24(3):561-87.

12. Fernando DJ. Knowledge about diabetes and metabolic control in diabetic patients. Ceylon Med J, 1993;38(1):18-21.

13. Metghalchi S, Rivera M, Beeson L, et al. Improved clinical outcomes using a culturally sensitive diabetes education program in a Hispanic population. Diabetes Educ, 2008;34(4):698-706.

14. Wheeler G, Montgomery SB, Beeson L, et al. En Balance: the effects of Spanish diabetes education on physical activity changes and diabetes control. Diabetes Educ, 2012;38(5):723-32.

15. Wing RR, Epstein LH, Norwalk MP, Scott N. Self-regulation in the treatment of type II diabetes. Behav Ther, 1988;19:11-23.

16. Sherifali D, Hess R, McTigue KM, Brozic A, $\mathrm{Ng} \mathrm{K}$, Gerstein H. Evaluating the feasibility and impact of an internet-based lifestyle management program in a diabetes care setting. Diabetes Technol Ther, 2014;16(6):358-62.

17. Wheeler LA, Wheeler ML, Ours P, Swider C. Evaluation of computer-based diet education in persons with diabetes mellitus and limited educational background. Diabetes care 1985;8(6):537-44.

18. Boren SA, Gunlock TL, Peeples MM, Krishna S. Computerized learning technologies for diabetes: a systematic review. J Diabetes $S c i$ Technol, 2008;2(1):139-46.

19. Tshiananga JK, Kocher S, Weber C, ErnyAlbrecht K, Berndt K, Neeser K. The effect of nurse-led diabetes self-management education on glycosylated hemoglobin and cardiovascular risk factors: a meta-analysis. Diabetes Educ 2012;38(1):108-23.

20. Wu SF, Lee MC, Liang SY, Lu YY, Wang TJ, Tung HH. Effectiveness of a self-efficacy program for persons with diabetes: a randomized controlled trial. Nurs Health Sci, 2011;13(3):335-43.
21. Wood ER. Evaluation of a hospital-based education program for patients with diabetes. J Am Diet Assoc, 1989;89(3):354-8.

22. Glasgow RE, Toobert DJ, Hampson SE, Brown JE, Lewinsohn PM, Donnelly J. Improving self-care among older patients with type II diabetes: the "Sixty Something..." Study. Patient Educ Couns, 1992;19(1):61-74.

23. Wierenga ME. Life-style modification for weight control to improve diabetes health status. Patient Educ Couns, 1994;23(1):33-40.

24. Deakin T, McShane CE, Cade JE, Williams RD. Group based training for selfmanagement strategies in people with type 2 diabetes mellitus. Cochrane Database Syst Rev, 2005(2):CD003417.

25. Barth R, Campbell LV, Allen S, Jupp JJ, Chisholm DJ. Intensive education improves knowledge, compliance, and foot problems in type 2 diabetes. Diabet Med, 1991;8(2):111-7.

26. A desktop guide to Type 2 diabetes mellitus. European Diabetes Policy Group 1999. Diabet Med, 1999;16(9):716-30.

27. Naccashian Z. The Impact of Diabetes SelfManagement Education on Glucose Management and Empowerment in Ethnic Armenians With Type 2 Diabetes. Diabetes Educ, 2014; 40(5):638-47.

28. Makki Awouda FO, Elmukashfi TA, Hag AlTom SA. Effects of health education of diabetic patient's knowledge at Diabetic Health Centers, Khartoum State, Sudan: 20072010. Glob J Health Sci 2014;6(2):221-6.

29. Gavin JR 3rd, Peterson K, Warren-Boulton E. Reducing cardiovascular disease risk in patients with type 2 diabetes: a message from the National Diabetes Education Program. Am Fam Physician, 2003;68(8):1569-74.

30. Abbate SL. Expanded ABCs of diabetes. Clin Diabetes, 2003;21:128-33.

31. Trento M, Passera P, Bajardi M, et al. Lifestyle intervention by group care prevents deterioration of Type II diabetes: a 4-year randomized controlled clinical trial. Diabetologia, 2002;45(9):1231-9.

32. Sperl-Hillen J, Beaton S, Fernandes O, et al. Are benefits from diabetes self-management education sustained? Am J Manag Care, 2013;19(2):104-12. 